\title{
Chronic thinner intoxication: clinico-pathologic report of a human case
}

\author{
ALFONSO ESCOBAR AND CRISTINA ARUFFO \\ From the Department of Neurobiology, Institute for Biomedical Research, National University of Mexico, \\ and Department of Pathology, National Institute of Neurology and Neurosurgery, Mexico
}

SUMMARY A 27 year old Mexican male addicted for 12 years to glue-sniffing and thinner inhalation developed neurological and behavioural disturbances which led to hospital admission and death. Autopsy disclosed diffuse cerebral and cerebellar cortex atrophy and giant axonopathy both central and peripheral. The corpus callosum was atrophic secondarily to neuron loss in the neocortex.

The deleterious effect of industrial solvents upon the central and peripheral nervous system is well known owing to the widespread use of these compounds both in industry ${ }^{1}$ and as a means of voluntary intoxication. ${ }^{2}$ The neurotoxins most commonly used for self-intoxication are compounds containing a variable mixture of toluene, benzene, acetone, methanol, and n-Hexane. In Mexico paint thinner or shoe cement are the most commonly used. ${ }^{3}$

Many clinical and experimental studies have been published in the past two decades and information gathered indicates that peripheral neuropathy ${ }^{4}$ and cerebellar cortex degeneration ${ }^{5}$ are among the most common pathologic changes found. Apparently the axons are highly vulnerable and develop the so-called "dying-back" phenomenon $^{6}$; however, the intrinsic mechanism of how damage ensues has not been completely elucidated. Recently Schoental and Cavanagh ${ }^{7}$ have suggested that these substances have an inhibitory or inactivating effect upon coenzymes linked directly to brain biochemical reactions.

Physiological and behavioural studies have shown that the limbic structures are severely affected and that the clinical symptomatology both in humans and in experimental animals varies from simple transitory confusional hallucinatory states to the production of petit-mal and grand-mal seizures. ${ }^{8-10}$ Pathological reports in humans are scarce ${ }^{11} 12$; the cerebellar and cer-

Address for reprint requests: Dr Alfonso Escobar, Department of Neurobiology, Institute for Biomedical Research, UNAM, Mexico 20, DF, Mexico.

Accepted 20 June 1980 ebral cortical atrophy induced by chronic lacquer-thinner intoxication in humans have been mainly documented on clinical grounds. ${ }^{13-15} \mathrm{Re}$ cently we have had the opportunity to study the case of a young man who was chronically addicted to neurotoxins containing lacquer-thinner; the clinical and neuropathological findings constitute the purpose of this report.

\section{Case history}

A twenty seven year old Mexican male was admitted to the National Institute of Neurology and Neurosurgery (INNN) in Mexico City with a 12 year history of glue-sniffing or thinner inhalation. Occasionally he smoked marihuana or ingested barbiturates. During the month prior to admission he was addicted solely to thinner inhalation. His relatives reported that within the past year he had been apathetic, and his personal appearance had deteriorated. He was irritable and was uninhibited using obscene expressions.

Three weeks before being admitted to the INNN the patient stopped eating and began to show gait unsteadiness with a tendency to fall to both sides, his speech became slurred and he developed urinary incontinence. At the time of admission his blood pressure was $120 / 90 \mathrm{mmHg}$, pulse rate $80 / \mathrm{min}$, temperature $36^{\circ} \mathrm{C}$, weight $50.5 \mathrm{Kg}$, height $1.50 \mathrm{~m}$. He was unable to walk unless aided, appeared confused, disoriented, dysarthric and retarded. Neurological examination showed bilateral horizontal nystagmus. There was paresis of both upper and lower limbs with generalised muscle atrophy and moderate hypotonicity; however, myotatic reflexes were 
increased and Babinski's sign was present bilaterally. Skin reflexes were abolished; palmar and prehension reflexes were positive. Deep sensibility in the lower limbs was decreased and there was total loss of superficial sensibility in all four extremities. It was concluded that the patient had a diffuse myeloencephalopathy secondary to the toxic effects of his chronic thinner inhalation.

A few days later dysmetria and dysdiadochokinesis in the left extremities were detected. Cerebrospinal fluid obtained by lumbar puncture showed normal opening pressure, no cells, $72 \mathrm{mg}$ of proteins per $\mathrm{dl}$ and $52 \mathrm{mg}$ of glucose per $\mathrm{dl}$; Nieto's complement-fixation reaction for cysticercosis and VDRL were negative.

Conduction velocity of the ulnar nerve was $30.5 \mathrm{~m} / \mathrm{s}$ (normal $49-55 \mathrm{~m} / \mathrm{s}$ ) a finding interpreted as a sign of peripheral neuropathy. The EEG tracing showed diffuse slow waves of medium voltage and was considered as slightly abnormal.
Computed tomography showed cerebral and cerebellar atrophy with prominence of the sulci at the level of the cerebral convexity and dilated lateral ventricles (fig 1).

The patient was treated with diazepam and trifluorperazine which did not modify his violent behaviour and obscene language; he was transferred to the psychiatric ward one week after entering the INNN. He was then given sedatives. A few days later hypostatic bilateral pneumonia developed which was confirmed by a chest X-ray. $\mathrm{He}$ was treated with antibiotics but finally died with deep cyanosis and respiratory insufficiency.

At necropsy it was confirmed that the patient had died of bilateral bronchopneumonia and there were signs of acute haemorrhagic gastritis. Neuropathological findings The brain weighed $1125 \mathrm{~g}$, the leptomeninges were moderately thickened; one half of the brain was peeled to expose

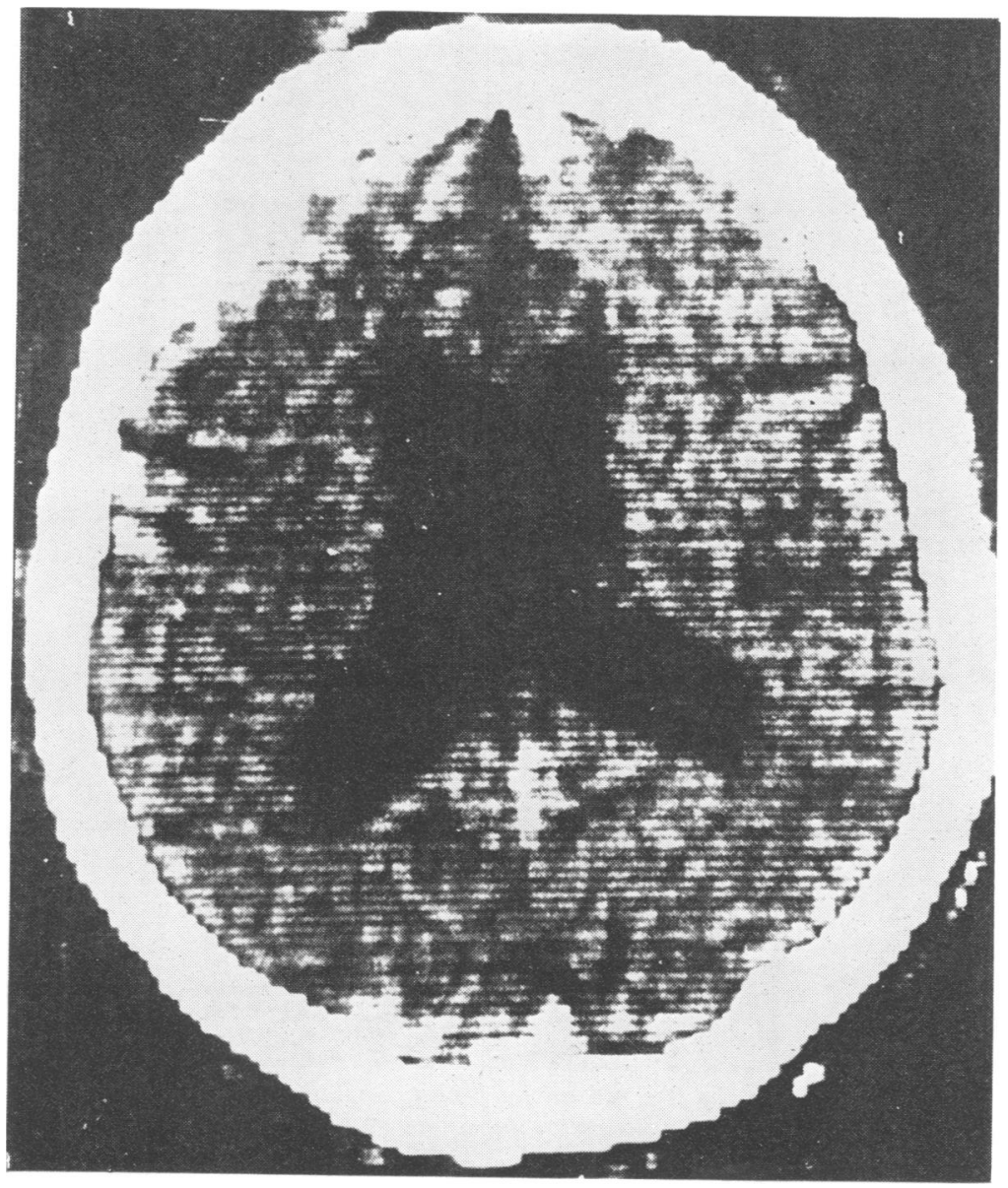

Fig 1 CT scan showing widening of the lateral ventricles and of the sulci. 
wide sulci. Coronal sections showed thinning of the cerebral cortex and corpus callosum, the latter being quite evident at the level of the interparietal connections (fig 2). The basal ganglia, especially the globus pallidus, were also diminished in size and had a peculiar yellowish colour. The lateral and third ventricles were dilated. The external surface of the cerebellum and brain stem were normal on naked-eye examination. The arteries of the circle of Willis and the cranial nerves appeared normal.

Histological examination included sections stained with haematoxylin and eosin, KlüverBarrera technique for myelin and nerve cells, and Holzer for glial fibres. Silver impregnation techniques were applied to frozen sections in order to demonstrate both axons and neuroglia. The cerebral cortex, basal ganglia, and cerebellum proved to be the most affected parts as shown by a diminished neuron density. The parietal cortex, in the association areas, was severely damaged, mainly the second, third and sixth layers (fig 3). Reactive gliosis was evident in both the white and gray matter. The astrocytic nuclei appeared to be of larger size than normal with scarce chromatin and a thin rim of eosinophilic cytoplasm surrounding them. Fragmented axons and vacuolation of the myelin sheaths and diffuse demyelination were evident in the subcortical white matter (fig 4). There was hyalinisation of the arterioles in the basal ganglia and in the deep cortical layers.

The cerebellar cortex was notably altered due to a severe deficit of Purkinje cells which was roughly estimated to amount to $70 \%$. The molecular layer showed a secondary isomorphic gliosis and there was evidence of demyelination in the white matter. Many of the axons of the remaining Purkinje cells showed "ballooning" of the proximal portion at the level of the granular layer (fig 5).

Giant axonal degeneration was seen in the

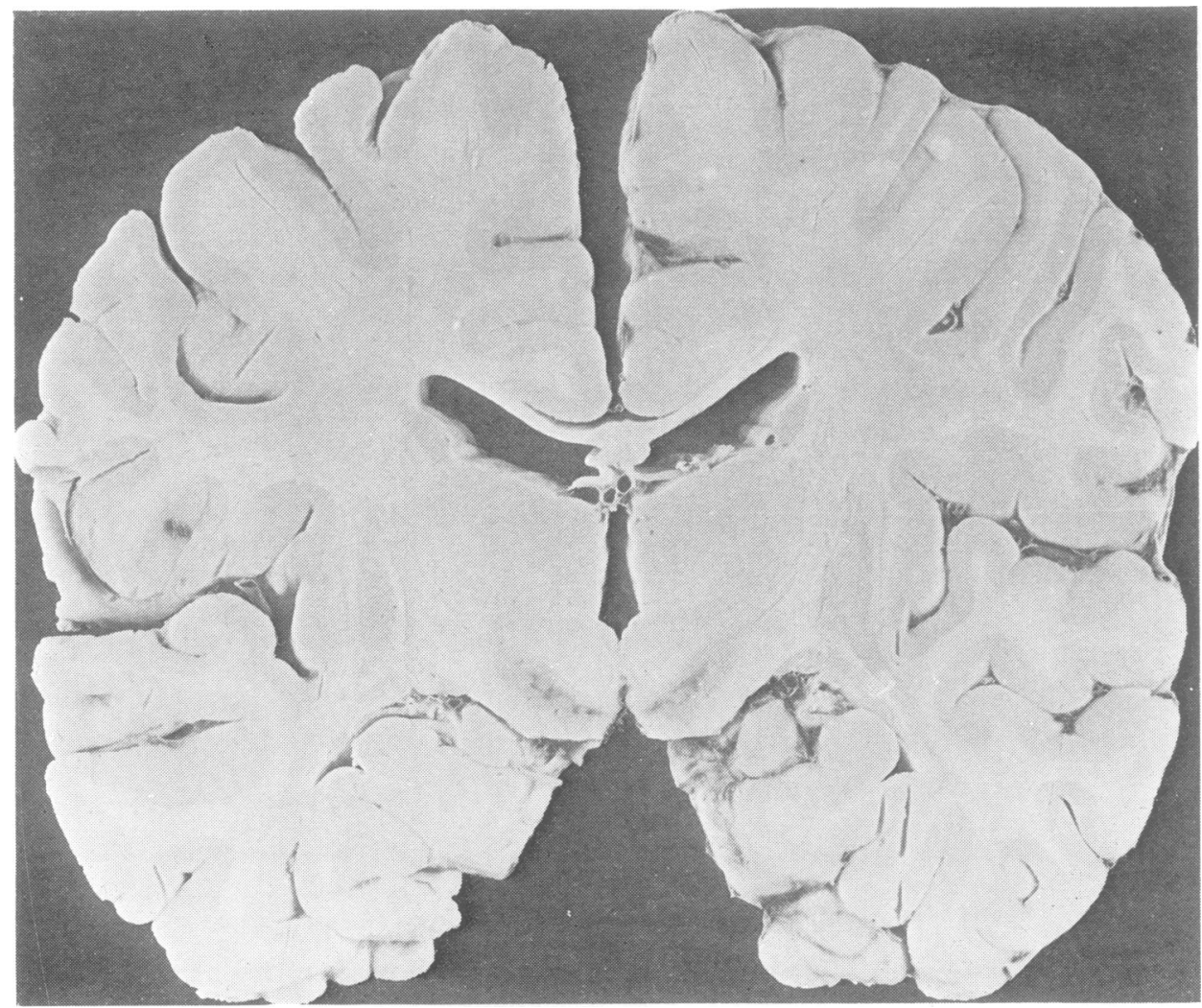

Fig 2 Coronal section at the level of the thalamus and the red nucleus. Notice widening of the ventricular cavities and the marked atrophy of the corpus callosum. Some of the convolutions show thinning of the cortex. $(\times 1 \cdot 2)$ 
Chronic thinner intoxication: clinico-pathologic report of a human case

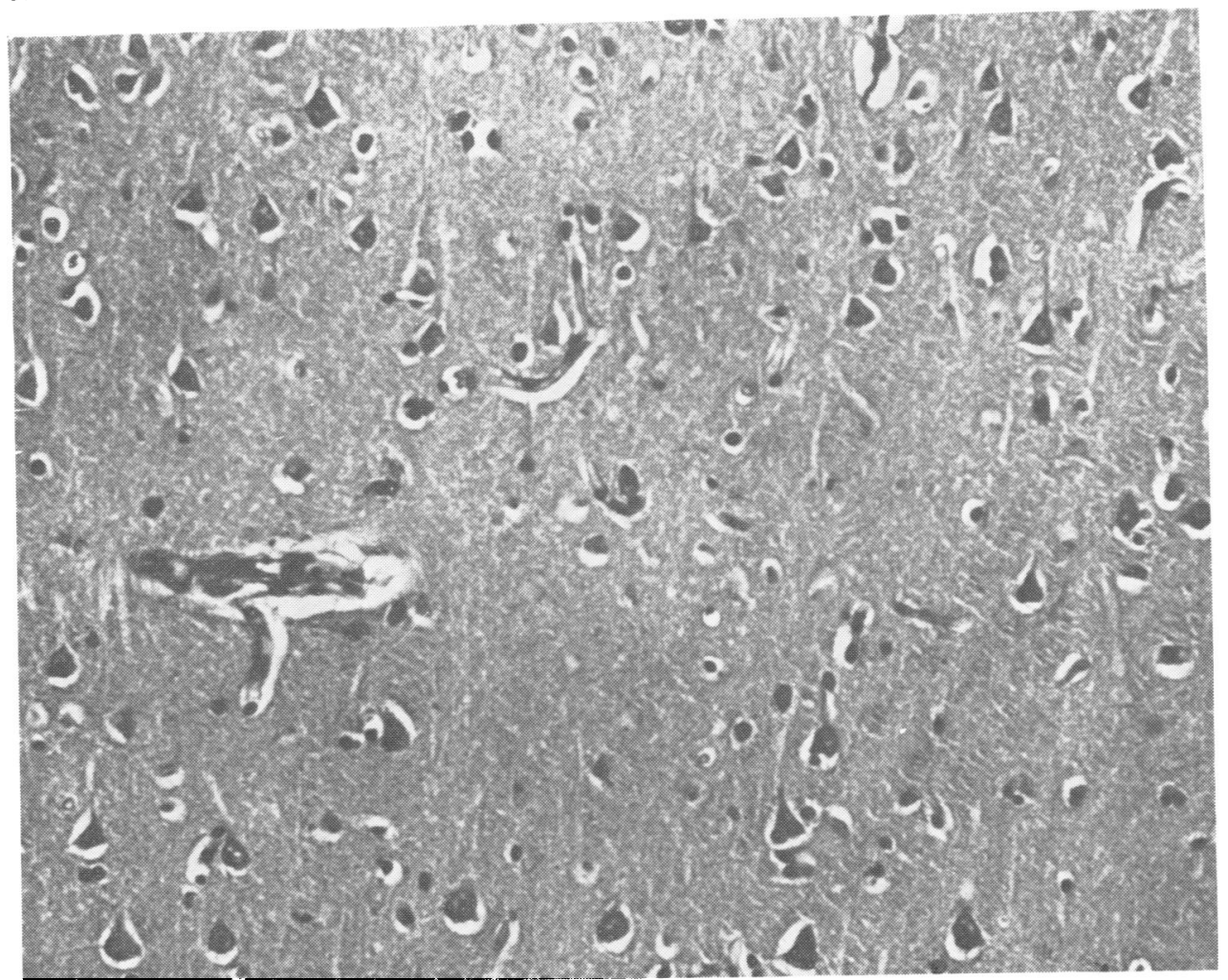

Fig 3 Photomicrograph of the parietal cortex. Notice the severe deficit in the neuron density. $H$ and $E$ method. $(\times 120)$

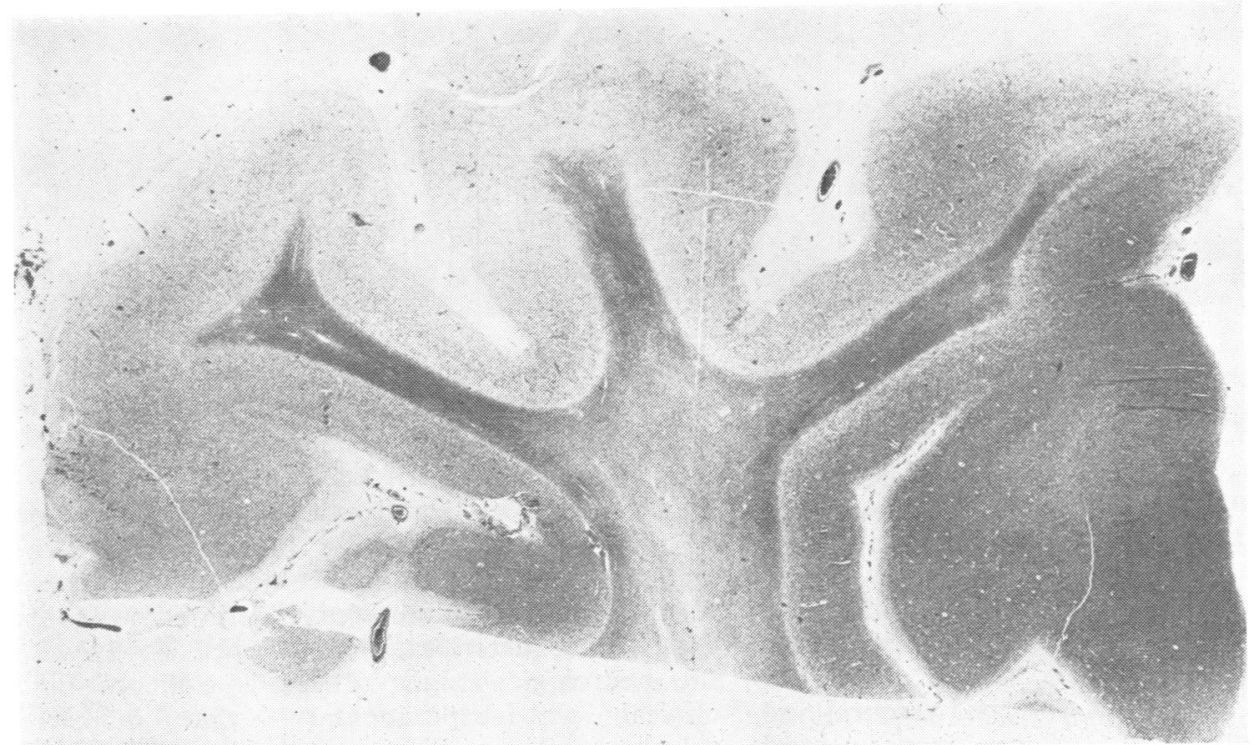

Fig 4 Panoramic view of the cerebral cortex. Notice diffuse demyelination in the white matter. Klüver-Barrera method. $(\times 6)$ 


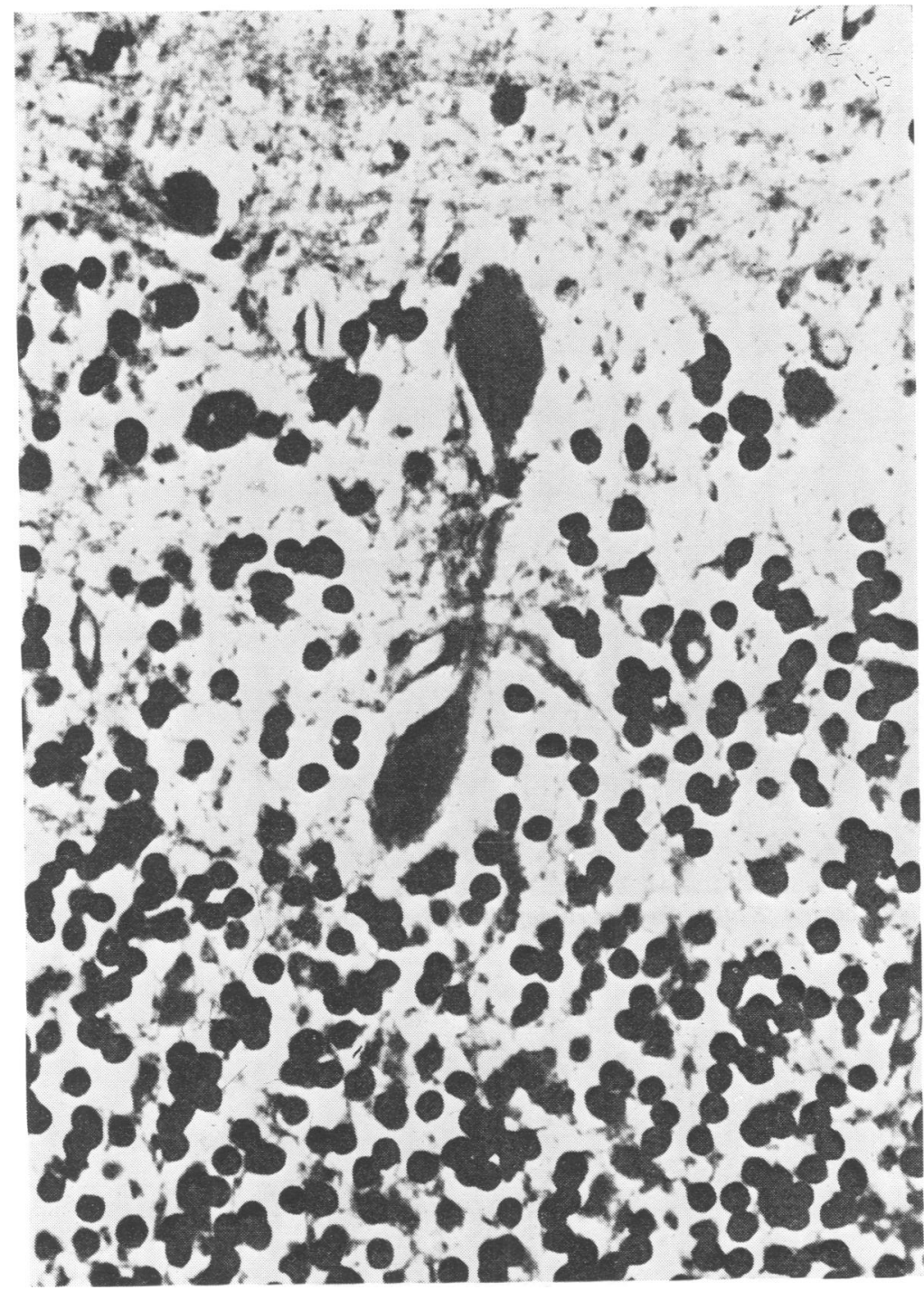

Fig 5 Ballooning of the axon of a Purkinje neuron in the cerebellum. Also notice the decreased density of the granular layer. $H$ and $E$ method. $(\times 450)$

white matter of the spinal cord, mainly in the posterior and lateral columns; the giant axons were enclosed in a very thin membrane and fine fibrillary structures were detected in their inside (fig 6). The corpus callosum appeared with diffuse demyelination and distinct glial fibre proliferation (figs 7 and 8). Axons and myelin in the peripheral nerves showed signs of neuropathy.

In summary there was a universal cerebral and cerebellar atrophy and giant axon central neuronopathy affecting the long ascending and descending tracts.

\section{Discussion}

It is not easy to establish a clear-cut correlation of the sequence of events in this case if the clinical findings are to be interpreted on the basis of the anatomical changes. There is no doubt that mental deterioration developed slowly with the neurological signs. There is evidence both clinical and experimental ${ }^{15}$ that industrial solvents such as thinner and some of its basic compounds, namely $n$-Hexane, ${ }^{4}$ can exert a directly deleterious effect upon the nervous tissue, 


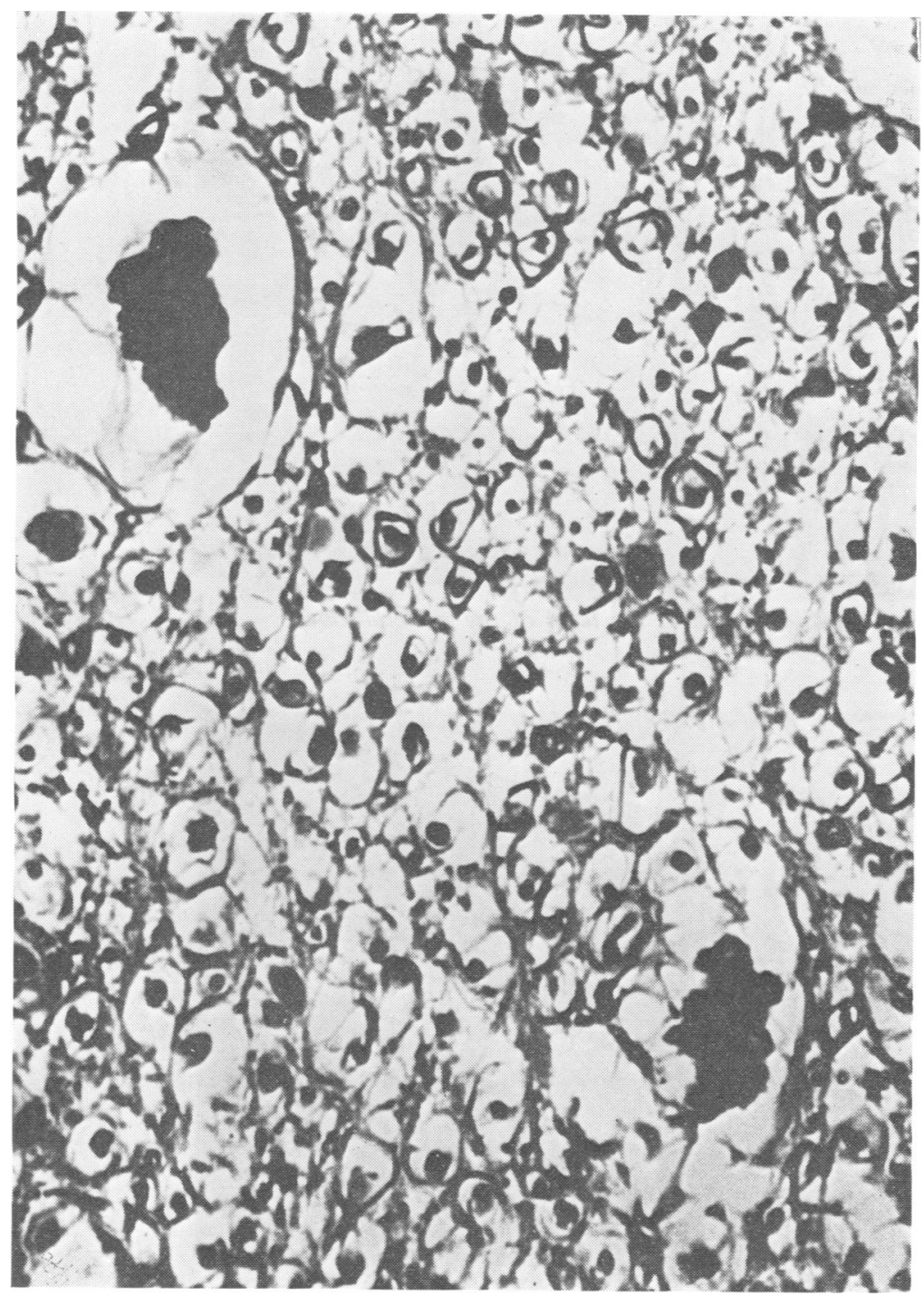

Fig 6 Cross section of the white matter of the cervical cord. The dark masses at upper left and lower right corners correspond to giant axons which were found scattered mainly along the diffuse demyelination and presence of reactive astrocytes. $H$ and $E$ method. $(\times 450)$

which may manifest itself as a psychosis. ${ }^{16}$ This patient had inhaled different compounds containing thinner, toluene and n-Hexane; hence there can be no doubt that the cerebral pathology can be linked to the deleterious effects of those compounds. Grabski ${ }^{13}$ has described a young man who was addicted to toluene inhaling associated with occasional trichloroethylene and methylethyl-ketone; the patient developed a cerebellar syndrome very similar to the one seen in our patient. Another case of cerebellar dysfunction was described by Kelly. ${ }^{14}$ Knox and Nelson ${ }^{15}$ followed-up the case described by Grabski ${ }^{13}$ which was reported as toluene encephalopathy in which damage to the central nervous system was diffuse and led to both motor and mental deterioration. The diagnosis in this case was confirmed by a pneumoencephalography which showed a marked widening both of the lateral ventricles and cortical sulci, especially in the frontal region. However, no necropsy studies were available in these human cases. ${ }^{13-15}$

The only pathological report of a human case of chronic lacquer-thinner intoxication refers mainly to peripheral neuropathy and long tract degeneration. ${ }^{11}$ One other human case of a chronic progressive encephalopathy due to gasoline sniffing ${ }^{12}$ showed only cerebellar cortex 


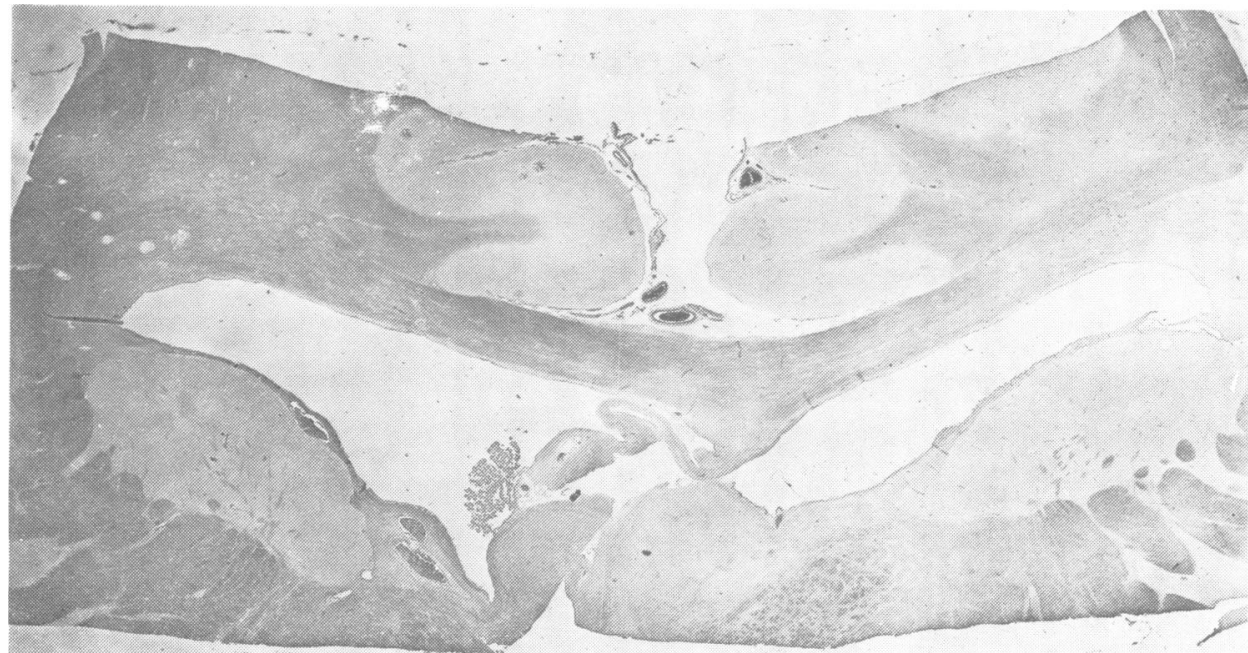

Fig 7 Diffuse demyelination of the corpus callosum at the level of the parietal lobes.

Klüver-Barrera method. $(\times 3)$

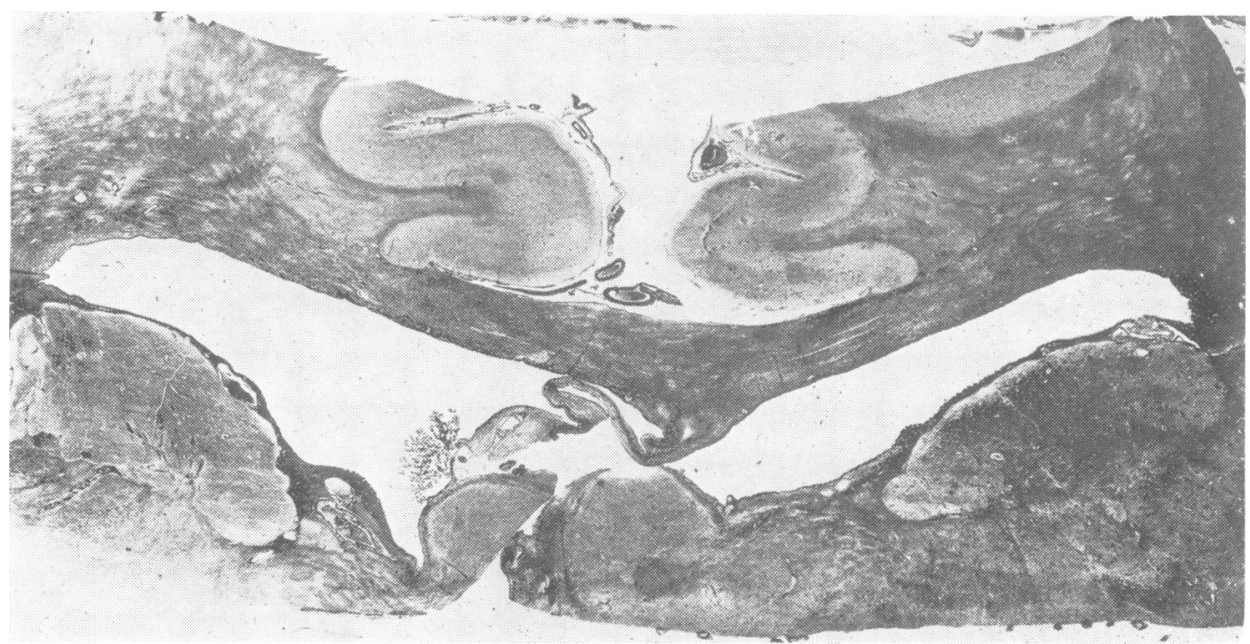

Fig 8 Heavy gliosis in the corpus callosum, extending into the adjacent subcortical white matter. Same section as in fig 7 . Holzer method. $(\times 3)$

atrophy and gliosis in subcortical structures, whilst the cerebral cortex was found normal; the central nervous system damage in this case was attributed to the toxic effect of organic lead contained in gasoline.

In the case presented here, the primary damage at the cortical level mainly affected the neurons in the second, third, and sixth layers of the neocortex. This led to the profound decrease in neuron density with a subsequent reduction in the neuropil, therefore leading to diffuse subcortical demyelination, and thinning of both the cortex and corpus callosum. The change in the corpus callosum was due to the loss of interhemispheric connections that originate primarily from the third and sixth layers. The cerebellar cortex was affected severely and most of the Purkinje cells were replaced by a diffuse gliosis; the remaining Purkinje cells already depicted degenerating changes in their axons such as "ballooning".

The effects of industrial solvents upon the peripheral nervous system are well established and giant axonal degeneration has been produced 
both clinically and experimentally by Schaumburg and Spencer. ${ }^{4}$ These authors found the changes both in the peripheral nerves and in the central nervous system long tracts; they have considered giant axonal degeneration as a sign of the "dying-back" process.

In the case reported here the findings in the brain and spinal cord must be evaluated as a direct effect of the compounds which were used to inhale. In Mexico industrial solvents such as available commercial thinner are a mixture composed of ethanol $4.5 \%$, methanol $15.1 \%$, acetone $1.9 \%$, benzene $0.13 \%$ and toluene $40 \%$, among other compounds. ${ }^{17}$ The Mexican thinner contains a high concentration of toluene which is the main agent responsible for brain damage in this case. It is interesting that giant-axonal degeneration was evident both in the long ascending and descending tracts in the spinal cord; however, no evidence of it was found in the corpus callosum. The possibility exists that it may have been present in an earlier stage of the cerebral damage since the intense gliosis indicated the long standing atrophy of the nerve fibres that form part of it. It is also possible that it may not have been detected in the slides examined.

In experimental animals it has been demonstrated that chronic thinner inhalation induces hallucinatory behaviour, hypermotility and ataxia. During the hypermotility the EEG tracing shows increased low-voltage fast frequency from the frontal cortex and reticular formation. However, when the hallucinatory behaviour appears the EEG tracing from the frontal region leads changes to high voltage slow waves very similar to the spike and wave complex with a frequency of 4-10 $\mathrm{Hz}$. The behavioural alterations vary depending on the concentration of the inhaling compound. ${ }^{8}$ More recently Contreras and associates, ${ }^{10}$ working with the cat, have been able to prove that chronic intoxication with thinner compounds induces EEG patterns triggered from the limbic structures that may manifest themselves as petit-mal and grandmal seizures. However, the EEG alterations were induced utilising thinner of higher concentrations than those commercially available industrial solvents. Perhaps this difference may explain why human cases do not show epileptic attacks. In the case here under study the EEG, though undoubtedly abnormal, only showed slow waves and clinically did not manifest epileptic convulsive symptoms. However, the overt behavioural alterations associated with hallucinatory episodes may indicate a manifestation of limbic dysfunction.
Owing to the increase in the use of industrial solvents, especially in the shoe industry as well as in paint factories, care should be taken with all the handlers of these compounds in order to prevent irreversible damage to the peripheral and central nervous system, which may end, in chronic cases of intoxication, in severe neurological or behavioural disability including profound dementia.

We thank Alejandro Puente, Salvador Puente and Artemio Guadarrama for their valuable technical aid.

\section{References}

1 Prockop LD. Nervous system damage secondary to inhalation of industrial solvents. In: Sharp $\mathrm{CW}$, Carroll LT, eds. Voluntary Inhalation of Industrial Solvents. Rockville MA: US Department of Health Education and Welfare, 1978: 198-209.

2 Glaser $\mathrm{HH}$, Massengale ON. Glue sniffing in children: deliberate inhalation of vaporised plastic cements. JAMA 1962; 181:300-3.

3 Lammoglia-Ruiz E. Inhalación de solventes y cementos plásticos por adolescentes. Rev Mexicana de Derecho Penal 1973; 4:1-21.

4 Schaumburg HH, Spencer PS. Degeneration in central and peripheral nervous systems produced by pure $n$-Hexane: an experimental study. Brain 1976; 99:183-92.

5 Baker AB, Tichy FY. The effects of the organic solvents and industrial poisonings on the central nervous system. Res Publ Assoc Res Nerv Ment Dis 1953; 32:475-505.

6 Cavanagh JB. The significance of the "dyingback" process in experimental and human neurological disease. Int Rev Exp Pathol 1964; 3: 219-67.

7 Schoental R, Cavanagh JB. Mechanisms involved in the "dying-back" process. An hypothesis implicating coenzymes. J Neuropathol App Neurobiol 1977; 3:145-57.

8 Alcaraz M, García-Castells E, Guzmán-Flores C. Efectos conductuales y electrográficos provocados por la inhalación aguda y crónica de tíner en el gato. In: Contreras-Pérez CM, ed. Inhalación Voluntaria de Disolventes Industriales. México: Trillas, 1977.

9 Guzmán-Flores C, Guzmán-López C. Alcaraz M. Efectos agudos del tíner sobre la conducta y la actividad eléctrica cerebral. Estudio experimental en el gato. Bol Estud Méd Biol 1974; 28:157-65.

10 Contreras CM, González-Estrada T, Zarabozo D, Fernández-Guardiola A. Petit mal and grand mal seizures produced by toluene or benzene intoxication in the cat. Electroencephalogr Clin Neurophysiol 1979; 46:290-301.

11 Means ED, Prockop LD, Hooper GS. Pathology 
of lacquer thinrer-induced neuropathy. $A n n$ Clin Lab Sci 1976; 6:240-50.

12 Valpey R, Sumi SM, Copass MK, Goble GJ. Acute and chronic progressive encephalopathy due to gasoline sniffing. Neurology (Minneap) 1978; 28:507-10.

13 Grabski DA. Toluene sniffing producing cerebellar degeneration. Am J Psychiatry 1961; 118: 461-2.

14 Kelly T. Prolonged cerebellar dysfunction asso- ciated with paint sniffing. Pediatrics 1975; 56: 605-6.

15 Knox J, Nelson IR. Permanent encephalopathy from toluene inhalation. $N$ Engl J Med 1966; 275:1494-6.

16 Glaser FB. Inhalation psychosis and related states. Arch Gen Psychiatry 1966; 14:315-22.

17 Gutiérrez-Flores RR. Solventes industriales. Cuadernos Científicos CEMEF (México), 1975; 2:49-58. 